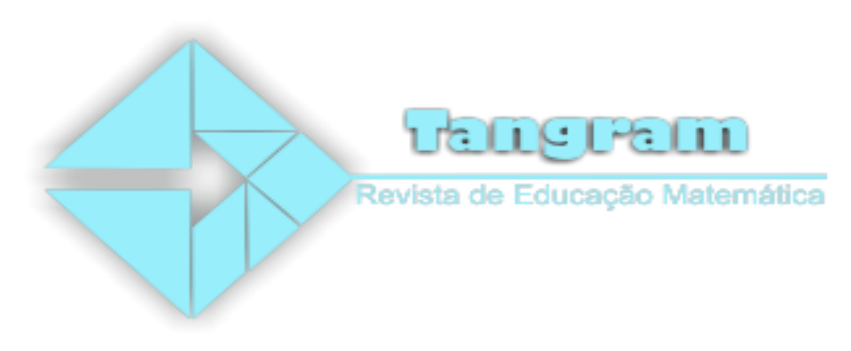

\title{
O juro real no contexto da educação financeira crítica
}

\section{The real interest in the context of critical financial education}

\author{
Celso Ribeiro Campos ${ }^{1}$ \\ Cileda Queiroz e Silva Coutinho ${ }^{2}$
}

Resumo:O objetivo deste trabalho é apresentar e aprofundar o conceito de letramento financeiro dentro da sua vertente crítica e descrever uma possibilidade de desenvolvimento prático dessas ideias em um projeto pedagógico que visa discutir o conceito de juro real no dia-a-dia dos brasileiros, favorecendo a reflexão e o debate sobre as problemáticas econômicas, sociais e políticas que derivam do tema proposto. Pretendemos demonstrar algumas possibilidades de trabalho com a educação financeira crítica, de modo a contribuir para o seu desenvolvimento e sua disseminação. A atividade pedagógica envolveu o cálculo da taxa real de juro considerando diversas medidas de inflação e de rendimento de operações financeiras. A educação crítica se fez presente na atividade e a modelagem matemática se mostrou adequada à proposta, abrindo espaço para discussões sobre problemas concretos que fazem parte da realidade dos alunos e que estão ligados à formação profissional deles. Palavras-chave: educação financeira; taxa real de juro; letramento financeiro

Abstract:The objective of this work is to present and deepen the concept of financial literacy within its critical stream and to describe a possibility of practical development of these ideas in a pedagogical project that aims to discuss the concept of real interest in Brazilians' daily life, favoring reflection and debate on the economic, social and political issues that derive from the proposed theme. We intend to demonstrate some possibilities of working with critical financial education, in order to contribute to its development and its dissemination. The pedagogical activity involved the calculation of the real interest rate considering several measures of inflation and income from financial operations. Critical education was present in the activity and the mathematical modeling proved adequate to the proposal, opening space for discussions about concrete problems that are part of the students' reality, which are linked to their professional training.

Key-words: financial education; real interest rate; financial literacy

1 Doutor em Educação Matemática pela UNESP-Rio Claro.Professor pesquisador do Programa de Estudos Pós-graduados em Educação Matemática da PUC-SP. Membro do grupo de pesquisa PEA-MAT, membro associado da SBEM e pesquisador colaborador do GT12 - Educação Estatística.

${ }^{2}$ Doutora em Didática da Matemática pela Université Joseph Fourier - Grenoble I, Professora do Programa de Estudos Pós-graduados em Educação Matemática da PUC-SP. Vice-coordenadora do grupo de pesquisa PEAMAT, no qual desenvolve pesquisas na área de Educação Estatística e Educação Financeira. Pesquisadora e colaboradora do GT12 - Ensino de Probabilidade e Estatítsica, da SBEM.

Tangram - Revista de Educação Matemática, Dourados - MS - v.2 n. 2, pp. 67 - 86 (2019) 


\section{O juro real no contexto da educação financeira crítica}

\section{Introdução}

A educação para o exercício da cidadania pressupõe que os estudantes devem ser estimulados a perceberem e exercerem seus direitos e deveres tanto em um sentido coletivo como individual, participando ativamente da vida em sociedade, respeitando ao outro, mas também exigindo respeito para si. Assim sendo, esse conceito de educação transcende as limitações das disciplinas escolares e se impõe como um objetivo maior e mais abrangente, que se sobrepõe inclusive ao tempo, pois pode e deve ser trabalhado desde os níveis mais básicos da vida estudantil.

Ao mesmo tempo, como Campos et al. (2011) afirmam, esse conceito se aproxima fortemente da ideia de Educação Crítica, na medida em que esta defende um ambiente pedagógico democrático, que busca o desenvolvimento, nos alunos, de um espírito crítico, responsabilidade ética e conscientização política.

Nessa linha, a vertente crítica da educação financeira está fortemente ligada ao conceito de letramento financeiro, que por sua vez deriva da ideia de alfabetização funcional e se articula com o conceito de matemacia (Coutinho e Campos, 2018).

Essa vertente assume pressupostos da educação crítica, que estão presentes em nosso entendimento sobre o letramento financeiro, o qual defende essencialmente uma postura crítica de valorização da conscientização social e política presente nos conhecimentos matemáticos, em particular naqueles ligados à matemática financeira que por sua vez interessam à educação financeira.

Com esse entendimento, buscamos a inserção da educação financeira no ensino da matemática financeira, o que acreditamos ser possível desde a educação básica até o nível superior. Os conteúdos de matemática financeira são pródigos em aplicabilidade à vida real dos cidadãos e igualmente possibilitam o trabalho com os conceitos de educação financeira, especialmente no que se refere ao letramento.

Lecionando a disciplina de Matemática Financeira em um curso de graduação de uma universidade privada na capital paulista, percebemos a possibilidade de trabalhar um projeto com os alunos voltado à discussão sobre o tema de juro real na economia brasileira. Percebemos a possibilidade de discussão de problemas econômicos, sociais e políticos ligados a esse tema, ao mesmo tempo em que seria possível desenvolver conceitos de

Tangram - Revista de Educação Matemática, Dourados - MS - v.2 n. 2, pp. 67 - 86 (2019) 


\section{O juro real no contexto da educação financeira crítica}

educação financeira por meio do letramento, ou seja, assumindo a vertente crítica como referência didática.

Dessa forma, o objetivo deste trabalho é apresentar e aprofundar o conceito de letramento financeiro dentro da vertente crítica que mencionamos e descrever uma possibilidade de desenvolvimento prático dessas ideias em um projeto pedagógico que visa discutir o conceito de juro real no dia-a-dia dos brasileiros, favorecendo a reflexão e o debate sobre as problemáticas econômicas, sociais e políticas que derivam do tema proposto.

Por um lado, não temos a intenção de validar quantitativamente a eficácia de uma estratégia pedagógica, nem advogar que tal estratégia é melhor ou pior que outras, até porque isso não coaduna com os pressupostos da educação crítica. Por outro lado, pretendemos demonstrar algumas possibilidades de trabalho com a educação financeira crítica, de modo a contribuir para o seu desenvolvimento e sua disseminação entre professores de matemática, pesquisadores e demais interessados no assunto.

\section{Quadro teórico}

\section{Sobre o letramento financeiro}

Em Coutinho e Campos (2018), discorremos sobre a articulação do letramento financeiro com a matemacia e, na ocasião, concordamos com Sena (2017), que assume como letramento financeiro:

- Habilidade de ler, analisar e interpretar situações financeiras;

- Conhecimento de elementos básicos e necessários à matemática financeira pertinente ao contexto dos sujeitos;

- Capacidade de assumir postura crítica fundamentada;

- Capacidade de considerar variáveis e implicações de suas ações;

- Tomada de decisões conscientes que visem o bem-estar financeiro individual e social. (Sena, 2017, p.39).

A congruência com a ideia de matemacia também é evidenciada em Coutinho e Campos (2018), na medida em que apresentamos e comparamos a noção de letramento financeiro com o que foi proposto por Skovsmose:

A ideia que tentei tornar significativa (mas não provar) é a seguinte: se $a$ alfabetização matemática tem um papel a desempenhar na educação similar mas não idêntico ao papel da alfabetização -, na tentativa de desenvolver uma competência democrática, então, a alfabetização matemática deve ser vista como composta por diferentes competências: matemática, tecnológica e reflexiva. E, acima de tudo o conhecimento reflexivo tem de ser desenvolvido para conferir à alfabetização matemática um poder radicalizado. (Skovsmose, 2001, p. 87-88, ênfase do autor)

Tangram - Revista de Educação Matemática, Dourados - MS - v.2 n. 2, pp. 67 - 86 (2019) 


\section{O juro real no contexto da educação financeira crítica}

A diferença entre os conhecimentos tecnológico e reflexivo é destacada em Campos (2007, p. 102):

O conhecimento matemático refere-se às habilidades de domínio de teoremas, algoritmos, demonstrações etc. Este conhecimento está mais ligado às atitudes tradicionalistas de ensino, cujo foco é o conteúdo.

$\mathrm{O}$ conhecimento tecnológico tem referência à aplicabilidade da Matemática e às competências na construção de modelos. Esse tipo de conhecimento se preocupa em usar a Matemática como ferramenta para alcançar objetivos tecnológicos.

O conhecimento reflexivo baseia-se em um amplo horizonte de interpretações, entendimentos e discussões que o conhecimento tecnológico em si não é capaz de desenvolver.

O conhecimento reflexivo foca na preparação dos alunos para uma vida social e política, habilitando-os a perceber, entender, julgar e aplicar a Matemática em seu cotidiano. Já o conhecimento tecnológico está mais voltado para a inserção do cidadão no mercado de trabalho, o que não é menos importante.

Adicionalmente, o conhecimento reflexivo valoriza o questionamento sobre os cálculos que estão sendo feitos, sobre a necessidade da formalização da matemática, a confiabilidade e as consequências dos resultados obtidos, etc., sem se preocupar em classificar tudo como certo ou errado. Dessa forma, o conhecimento reflexivo vai de encontro à ideologia do falso-verdadeiro (ideologia da certeza), comum no conhecimento matemático, segundo a qual qualquer resposta a um exercício tem de estar ou certa ou errada. Segundo Skovsmose (2004), o desenvolvimento do conhecimento reflexivo deve ser efetuado conjuntamente com o conhecimento tecnológico, devendo somar-se a este para constituir a competência democrática.

Em resumo, o referencial teórico-conceitual indispensável para o desenvolvimento da competência democrática inerente ao conceito de letramento financeiro inclui: os conhecimentos matemático e financeiro propriamente ditos, o conhecimento tecnológico e o conhecimento reflexivo.

Os princípios orientadores da Educação Matemática não são mais encontrados exclusivamente na Matemática pura, nem na aplicada, mas em uma perspectiva mais abrangente que objetiva o conhecimento reflexivo (Skovsmose, op. cit., p. 95).

Com isso, buscamos esclarecer nosso entendimento ligado ao letramento financeiro, que assume essencialmente uma postura crítica de valorização da conscientização social e política presente nos conhecimentos matemáticos, em particular naqueles ligados à

Tangram - Revista de Educação Matemática, Dourados - MS - v.2 n. 2, pp. 67 - 86 (2019) 


\section{O juro real no contexto da educação financeira crítica}

matemática financeira que por sua vez interessam à educação financeira, conjuntamente com o conhecimento reflexivo e a competência democrática.

\section{Sobre o juro real}

\section{a) Inflação}

De acordo com Hazzan e Pompeo (2007, p. 81), a inflação é um fenômeno caracterizado pelo "aumento persistente dos preços de bens e serviços", cuja consequência é a perda do poder aquisitivo da moeda, sendo essa perda tanto maior quanto maior for o aumento dos preços. Mesmo tendo a inflação controlada e estável em níveis historicamente baixos no Brasil (Gráfico 1), ela não deixa de provocar impacto sobre a rentabilidade das aplicações financeiras.

Hazzan e Pompeo (op. cit., pp. 81-82) pontuam que:

Em virtude de a alta taxa de inflação corroer rapidamente o poder aquisitivo da moeda, é fundamental analisar a relação das taxas de juros com as taxas de inflação. Muitas vezes uma aplicação financeira produz resultados que são meramente ilusórios, quando o aplicador não leva em conta a inflação.

Observamos que apesar de a inflação anual estar em patamares relativamente baixos, ela não é desprezível e o impacto que ela pode provocar nas aplicações financeiras fica mais evidente em operações de longo prazo, como por exemplo em planos de previdência privada.

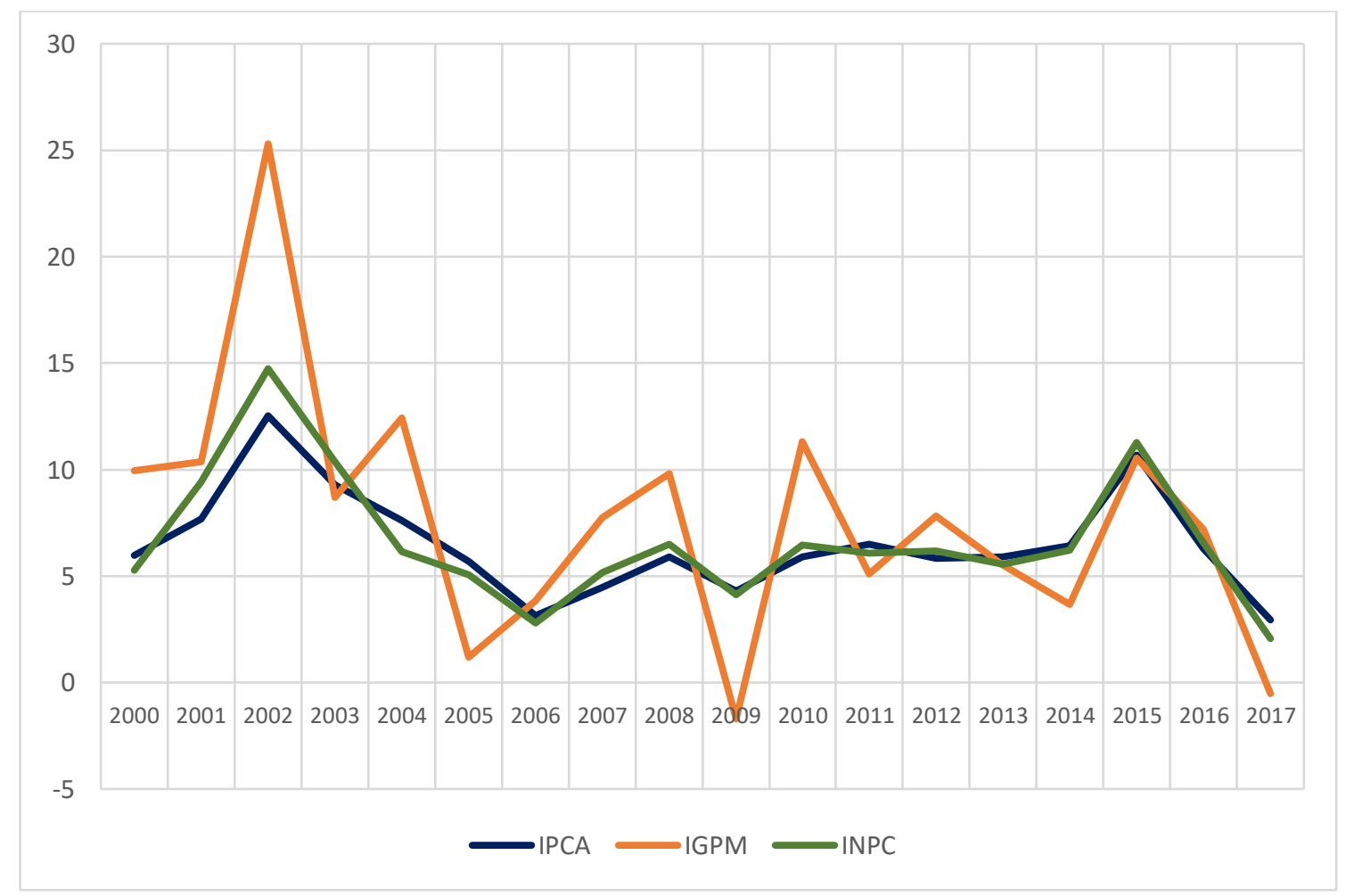

Gráfico 1: Inflação em \% ao ano. Fonte: elaboração própria com dados de www.portalbrasil.net Tangram - Revista de Educação Matemática, Dourados - MS - v.2 n. 2, pp. 67 - 86 (2019) 


\section{O juro real no contexto da educação financeira crítica}

Complementarmente, Faro (2006, p. 100) observa que:

Dado que a inflação se traduz no aumento dos preços dos bens e serviços transacionados na economia, sua medida deve procurar refletir esse aumento como um todo. Como, de uma maneira geral, o processo inflacionário não se manifesta de maneira uniforme, no sentido de que todos os preços na economia sofram a mesma variação, e como, ao menos para períodos pequenos, não é factível um acompanhamento de todos os preços, torna-se necessário que a medida da inflação seja efetuada considerando-se agregados bem definidos de bens e serviços.

No gráfico 1 nós mostramos o IPCA, que é o Índice de Preços ao Consumidor Amplo, calculado pelo Instituto Brasileiro de Geografia e Estatística (IBGE), que mede a inflação baseado em uma cesta de produtos consumidos pelas famílias com renda entre 1 e 40 salários mínimos. Esse índice serve de base para o sistema de metas de inflação adotado pelo Banco Central do Brasil (BCB), sendo por isso uma referência bastante utilizada para a medida da inflação. Contudo, ele não é o único índice confiável para medir a inflação no Brasil. $\mathrm{O}$ Índice Nacional de Preços ao Consumidor (INPC), também mostrado no gráfico 1, calcula a inflação com base no consumo das famílias com renda entre 1 a 5 salários mínimos. Segundo o IBGE (2018, sem página):

O Índice Nacional de Preços ao Consumidor - INPC que tem por objetivo a correção do poder de compra dos salários, através da mensuração das variações de preços da cesta de consumo da população assalariada com mais baixo rendimento. Esta faixa de renda foi criada com o objetivo de garantir uma cobertura populacional de $50 \%$ das famílias cuja pessoa de referência é assalariada e pertencente às áreas urbanas de cobertura do SNIPC - Sistema Nacional de Índices de Preços ao Consumidor.

Já o Índice Geral de Preços do Mercado (IGP-M), que também aparece no gráfico 1, calculado pela Fundação Getúlio Vargas (FGV) foi concebido para ser uma referência para a remuneração de alguns títulos emitidos pelo Tesouro Nacional e Depósitos Bancários com juro pós-fixados acima de um ano, mas posteriormente passou também a ser referência para correção de contratos de aluguel e para indexar tarifas, tais como a energia elétrica. Esse índice é composto pelo índice de preços por atacado (IPA), com peso de 60\%, o índice de preços ao consumidor (IPC), com peso de $30 \%$ e o índice nacional da construção civil (INCC), com peso de $10 \%$.

Como se vê, os índices mencionados têm concepções distintas e geram resultados diferentes para o cálculo da inflação. Adicionalmente, existem ainda outros índices importantes, como o IGP-DI (disponibilidade interna), o ICV (índice de custo de vida), etc. Logo, não há uma única medida da inflação, assim como não há um índice melhor que outro, pois as finalidades é que devem apontar qual deles é mais adequado.

Tangram - Revista de Educação Matemática, Dourados - MS - v.2 n. 2, pp. 67 - 86 (2019) 


\section{O juro real no contexto da educação financeira crítica}

\section{b) A taxa de juro real}

Seja $r$ a taxa de juro real, $i$ a taxa de remuneração efetiva de uma aplicação financeira e $j$ a taxa de inflação no período, Hazzan e Pompeo (2007) definem a seguinte relação para a taxa real de juro:

$$
1+r=\frac{1+i}{1+j}
$$

A taxa efetiva $(i)$ é definida como aquela que efetivamente verifica a operação financeira. Já a taxa de inflação $j$ deve ser a mais adequada para medir a variação dos preços, tendo-se em conta a realidade de quem está fazendo a aplicação financeira.

Dito isso, percebemos que há um problema na definição da taxa $j$, o qual os livros consultados de matemática financeira não mencionam.

Da mesma forma, pode-se dizer que há outro problema na determinação da taxa $i$, pois a remuneração das aplicações financeiras é bastante variável conforme o tipo de investimento: poupança, $\mathrm{CDB}, \mathrm{CDI}^{3}$, tesouro direto, etc.

Outro agravante ocorre no caso de haver uma necessidade de conversão cambial. Nesse caso, há que se considerar a variação da moeda para que se possa obter com mais precisão a remuneração real do investimento.

Adicionalmente, a taxa efetiva não reflete necessariamente a remuneração da aplicação financeira, pois investimentos em $\mathrm{CDB}$, tesouro direto e outros sofrem descontos de imposto de renda, o que não ocorre com a poupança, por exemplo.

Por conseguinte, o conceito de taxa real de juro não é trivial e o seu cálculo não se resume à aplicação de uma fórmula, pois há que se justificar as escolhas feitas para a taxa de remuneração dos investimentos, assim como para a taxa de inflação.

\section{Procedimentos metodológicos}

\section{A modelagem matemática}

A estratégia pedagógica que vamos mostrar neste trabalho foi concebida no âmbito da modelagem matemática.

A modelagem consiste na arte de criar modelos para os mais diversos fins e pode ser vista como uma forma de constituição e de expressão do conhecimento. A Matemática e a

\footnotetext{
${ }^{3}$ Certificado de Depósito Interbancário, corresponde a uma taxa calculada pela CETIP para remunerar empréstimos de curtíssimo prazo (1 dia) feitos entre os bancos. Essa taxa serve de referência para remuneração de diversas aplicações financeiras e geralmente é bem próxima à taxa SELIC.
}

Tangram - Revista de Educação Matemática, Dourados - MS - v.2 n. 2, pp. 67 - 86 (2019) 


\section{O juro real no contexto da educação financeira crítica}

Estatística são particularmente pródigas na possibilidade de criar modelos, na medida em que qualquer problema quantificável requer a intervenção de um ente matemático. Dessa forma, a Matemática e a realidade podem ser conectadas por meio da modelagem e o processo que envolve a obtenção de um modelo matemático é conhecido como modelagem matemática. Ela é feita mediante o uso dos processos matemáticos conhecidos com o objetivo de estudar, analisar, explicar ou prever situações do mundo real que nos cerca.

A validade ou a riqueza do modelo não está somente ligada à sofisticação matemática que o envolve, mas à sua capacidade de explicação, de predição, de adaptação, de adequação e de aplicação em diferentes contextos, como também ao seu potencial de provocar reflexões e discussões sobre as situações da realidade (Campos \& Wodewotzki, 2007, p. 323)

D’Ambrosio (1991) relaciona a modelagem com a reflexão. Para ele, ao se empreender esforços para explicar, entender, manejar um recorte da realidade, obtém-se um modelo e passa-se à reflexão sobre ele. Essa reflexão leva à ação, quando se promove a solução do problema e se valida o seu resultado.

A modelagem também se apresenta como uma forma de despertar nos estudantes o interesse pela disciplina, na medida em que eles têm a oportunidade de desenvolver projetos que têm aplicação concreta e que permitem exercer uma reflexão sobre aspectos que são relevantes para a sociedade, buscar explicações para os fenômenos estudados, discutir sobre eles, valorizando o seu senso crítico (Campos \& Wodewotzki, 2007, p. 323 ).

Nessa perspectiva da modelagem matemática como uma metodologia ou estratégia pedagógica, consideramos adequado conceituá-la da mesma forma que Barbosa (2007), como um ambiente de aprendizagem (a ser construído na sala de aula) em que os estudantes são convidados (pelo professor) para investigar, por meio da matemática, situaçõesproblema extraídas do dia-a-dia, ou mesmo de outras ciências. Dessa forma, Segundo Campos et al. (2011, pp. 48-49),

[...] o processo de modelagem deve ter o seu início e o seu término no mundo real, passando por investigações e por reflexões que fundamentem a construção ou a escolha de modelos matemáticos, pelas etapas de validação e de interpretação de resultados, pela sistematização do conteúdo etc.

A modelagem configura-se, então, como uma estratégia de ensino-aprendizagem que pode ser performada por meio de projetos pedagógicos, nos quais os alunos preferencialmente trabalham em grupo. Esses projetos são desenvolvidos em três etapas:

a) Interação: reconhecimento da situação-problema e familiarização com o tema a ser abordado; construção do referencial teórico.

Tangram - Revista de Educação Matemática, Dourados - MS - v.2 n. 2, pp. 67 - 86 (2019) 


\title{
O juro real no contexto da educação financeira crítica
}

b) Matematização: formulação do problema, criação de hipóteses e resolução do problema.

c) Modelo matemático: interpretação da solução e validação do modelo.

Nossa perspectiva sobre a modelagem matemática inclui e enfatiza sua vertente sócio-crítica, observada em Barbosa (2003, 2006 e 2007), Kaiser e Sriraman (2006), Campos (2007), Campos et al. (2011), entre outros. Essa vertente destaca que a modelagem é

\begin{abstract}
uma oportunidade para os estudantes discutirem o papel da matemática na sociedade e a natureza dos modelos matemáticos. o desenvolvimento das competências ou a aprendizagem dos conceitos e procedimentos matemáticos, vistos em outras perspectivas como propostas primárias, é considerado na perspectiva sócio-crítica como um meio para possibilitar a discussão dos papéis que aqueles modelos matemáticos podem ter na sociedade (Barbosa, 2007, p. 2101).
\end{abstract}

Essa perspectiva, aplicada à Educação Financeira, coaduna com a sua vertente crítica, na medida em que dialoga com uma abordagem humanitária, com objetivo de promover a inclusão social e econômica e promover o empoderamento individual.

\section{A estratégia pedagógica}

No primeiro semestre de 2018, em uma turma de $3^{\circ}$ semestre de um curso de graduação em Ciências Econômicas, dado por uma universidade privada da cidade de São Paulo, na disciplina de Matemática Financeira ministrada pelo primeiro autor deste trabalho, discutimos com os alunos o conceito de juro real e apresentamos a sua fórmula de cálculo. Debatemos sobre as várias possibilidades para referenciar tanto o índice de inflação quanto a taxa efetiva da aplicação financeira.

O debate foi profícuo e várias possibilidades de cálculo foram citadas pelos alunos, que igualmente discutiram sobre a adequação das variáveis envolvidas na determinação da taxa real.

Diante do bom envolvimento dos alunos no tema, eles foram convidados pelo professor a pesquisarem e apresentarem uma possibilidade de cálculo da taxa real, justificando suas escolhas. A turma foi então livremente dividida em cinco grupos com quatro participantes cada e foi acordado um prazo de duas semanas para os alunos prepararem um relatório e fazerem uma breve apresentação.

Para uniformização dos resultados, professor e alunos concordaram em fazer análises históricas de índices de inflação e de rendimento de aplicações financeiras pelo período de dez anos, ou seja, de 2008 a 2017; cálculo da taxa real de juro para o mês de fevereiro de

Tangram - Revista de Educação Matemática, Dourados - MS - v.2 n. 2, pp. 67 - 86 (2019) 


\section{O juro real no contexto da educação financeira crítica}

2018; confecção de um gráfico em linhas para mostrar a evolução da taxa de inflação segundo o índice escolhido junto com a taxa efetiva usada no cálculo.

Ficou combinado que os grupos deveriam discutir com o professor a respeito de suas escolhas, de modo a evitar que dois grupos apresentassem ideias e cálculos iguais ou muito semelhantes por vincularem as mesmas variáveis. Uma semana antes da data marcada, os grupos procuraram o professor para dirimir dúvidas quanto aos cálculos realizados, bem como em relação aos gráficos que eles deveriam preparar e a fonte na qual eles deveriam buscar os índices ${ }^{4}$.

No dia marcado, os alunos fizeram as apresentações, as quais descrevemos resumidamente na sequência.

\section{Resultados}

A seguir, vamos descrever os resultados separados em três partes, a saber: as apresentações, os relatórios e os debates.

\section{As apresentações}

O grupo 1 decidiu fazer o cálculo da taxa de juro real considerando a remuneração do FGTS (Fundo de Garantia por Tempo de Serviço), que os trabalhadores com registro formal têm. A taxa de inflação escolhida pelo grupo foi o Índice do Custo de Vida, calculado pelo Departamento Intersindical de Estatística e Estudos Socioeconômicos (DIEESE), que é um índice calculado mensalmente no município de São Paulo, com base em uma cesta de produtos e serviços obtida por meio da Pesquisa de Orçamento Familiar (POF). Na sua apresentação, o grupo mostrou um gráfico contendo os valores da remuneração do FGTS e do ICV para um período de dez anos (Gráfico 2).

\footnotetext{
${ }^{4} \mathrm{O}$ professor indicou o site http://www.portalbrasil.net

Tangram - Revista de Educação Matemática, Dourados - MS - v.2 n. 2, pp. 67 - 86 (2019)
} 


\section{O juro real no contexto da educação financeira crítica}

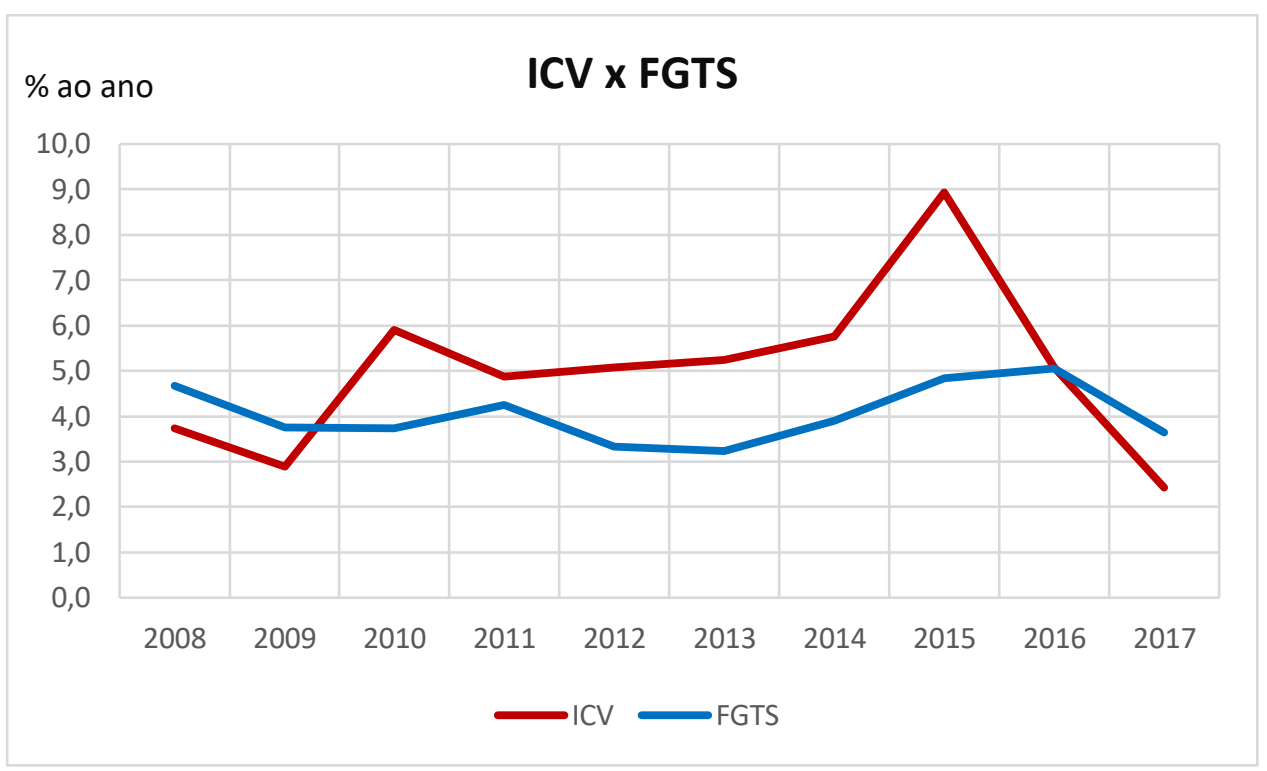

Gráfico 2: Inflação em \% ao ano (ICV) e remuneração do FGTS. Fonte: dados de http://www.portalbrasil.net/tr_mensal.htm, apud relatório dos estudantes

Ao mostrar o gráfico, o grupo comentou que entre 2010 e 2016 o trabalhador amargou juros reais negativos em sua conta do FGTS. Para o mês de fevereiro de 2018, o grupo mostrou o cálculo da taxa real de juro mensal:

$$
\begin{gathered}
1+r=\frac{1+i}{1+j}=\frac{1+0,0025}{1+0,0005}=1,002 \\
r=1,002-1=0,002 \text { ou } 0,2 \%
\end{gathered}
$$

O grupo explicou que a remuneração do FGTS, que usualmente corresponde a 3\% ao ano (nominal) mais TR (Taxa Referencial), agora se resume a 3\% ao ano ou 0,25\% ao mês, pois a TR é nula desde outubro de 2017.

O grupo justificou sua escolha pelo FGTS e ICV para obter o valor da taxa real de juro para o trabalhador brasileiro.

O grupo 2 escolheu fazer o cálculo da taxa de juro real considerando a remuneração da poupança e o índice de inflação dado pelo INPC, justificando a escolha como sendo uma forma de obter a taxa real de juro obtida pela parte da população que consegue fazer o investimento mais popular do país, que é a poupança, mesmo tendo remuneração baixa, ou seja, renda baixa. O grupo mostrou um gráfico com a evolução histórica dos últimos dez anos para as variáveis escolhidas (gráfico 3).

Foi destacado pelo grupo que, à exceção do ano de 2015, nos demais anos a remuneração da poupança superou a inflação medida pelo INPC, com destaque para o ano de 2017. Com relação ao valor atual da taxa real de juro com base nesses indicadores, o Tangram - Revista de Educação Matemática, Dourados - MS - v.2 n. 2, pp. 67 - 86 (2019) 


\section{O juro real no contexto da educação financeira crítica}

grupo mostrou que em fevereiro de 2018 o INPC foi de $0,18 \%$, enquanto a remuneração da poupança foi de $0,3994 \%$, o que resulta em uma taxa real dada por:

$$
\begin{gathered}
1+r=\frac{1+i}{1+j}=\frac{1+0,003994}{1+0,0018}=1,0022 \\
r=1,0022-1=0,0022 \text { ou } 0,22 \%
\end{gathered}
$$

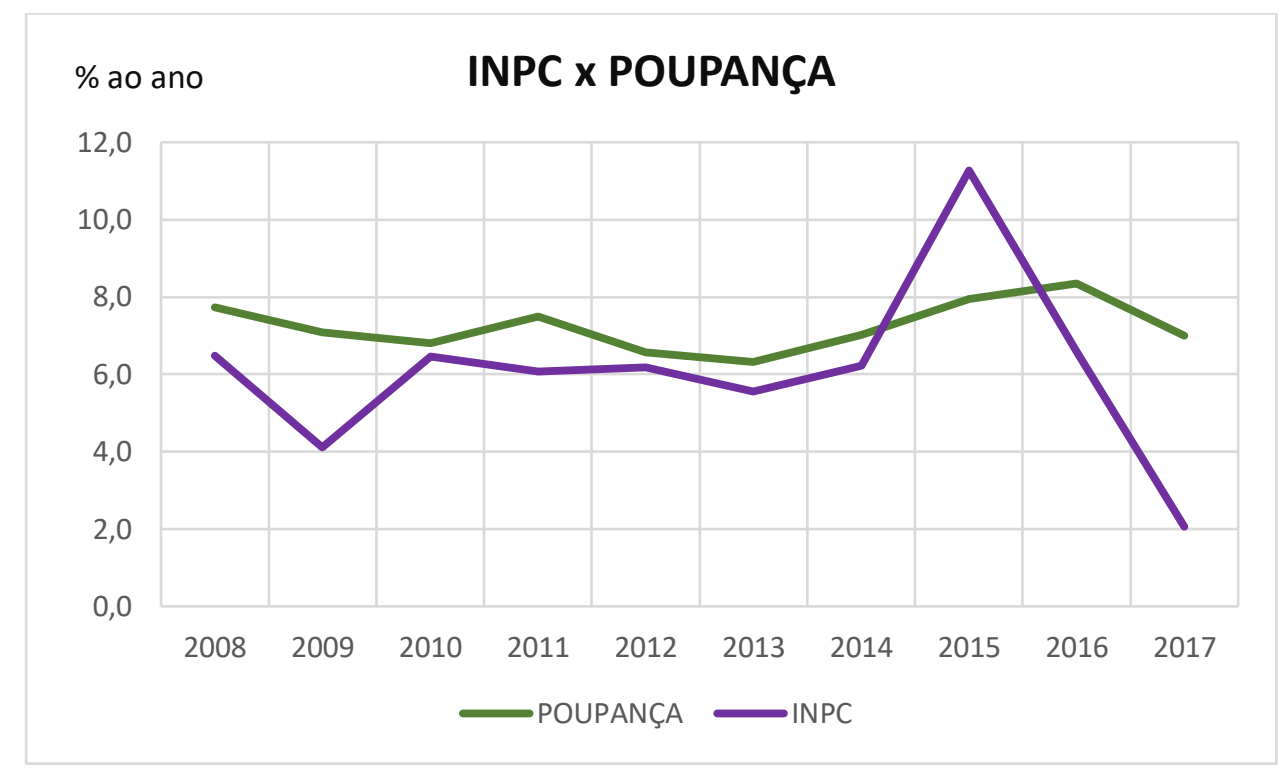

Gráfico 3: Inflação em \% ao ano (INPC) e remuneração da poupança. Fonte: dados de http://www.portalbrasil.net/inpc.htm, apud relatório dos estudantes

O grupo pontuou ainda que o INPC é um índice calculado pelo IBGE e corresponde à inflação calculada com base em uma cesta de produtos consumidos pelas famílias com renda de 1 a 5 salários mínimos, sendo, portanto, um índice adequado para medir a inflação para a população de baixa renda.

O grupo 3 calculou a taxa real de juro baseada no IPCA, calculado pelo IBGE, como medida da inflação, e a taxa do CDI como medida da remuneração das aplicações financeiras. A evolução histórica dessas taxas foi mostrada pelo grupo por meio de um gráfico, reproduzido na sequência.

Tangram - Revista de Educação Matemática, Dourados - MS - v.2 n. 2, pp. 67 - 86 (2019) 


\section{O juro real no contexto da educação financeira crítica}

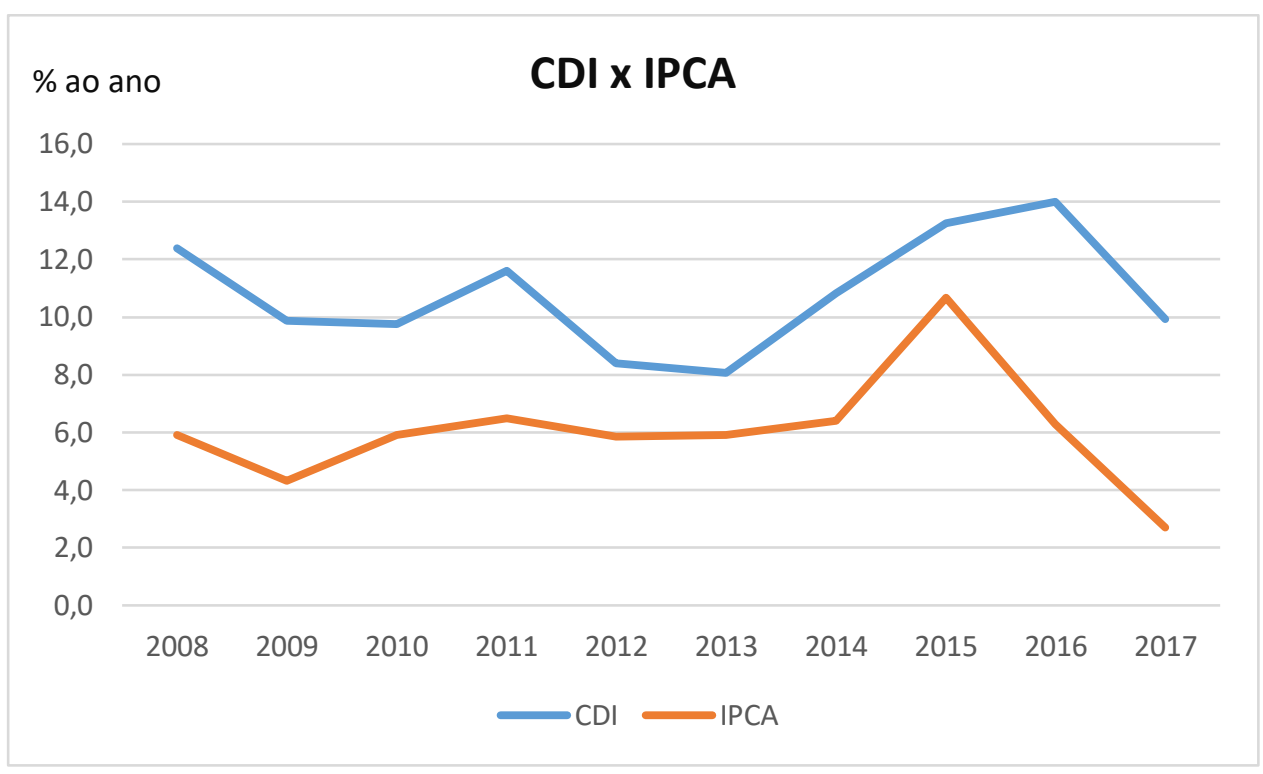

Gráfico 4: Inflação em \% ao ano (IPCA) e taxa do CDI. Fonte: dados de http://www.portalbrasil.net/indices_cdi.htm, apud relatório dos estudantes

O grupo mostrou que ao longo da série histórica a remuneração do CDI sempre esteve acima da inflação medida pelo IPCA, indicando que quem fez aplicações nessa modalidade de investimento pôde obter juros reais positivos ao longo dos últimos dez anos. Em relação à taxa de juro real referente ao mês de fevereiro de 2018, o grupo mostrou os cálculos feitos com uma taxa CDI de 0,4649\% e IPCA de 0,29\%:

$$
\begin{aligned}
& 1+r=\frac{1+i}{1+j}=\frac{1+0,004649}{1+0,0029}=1,001744 \\
& r=1,001744-1=0,001744 \text { ou } 0,1744 \%
\end{aligned}
$$

O grupo finalizou sua apresentação destacando que o IPCA é um índice de inflação baseado na cesta de consumo das famílias com renda de 1 a 40 salários mínimos e que as aplicações financeiras que rendem pela taxa do CDI são, em geral, disponibilizadas para grandes quantias de recursos, ou seja, essa realidade de juro real não corresponde ao que uma família de baixa renda poderia obter, pelo contrário corresponde à remuneração dos chamados rentistas 5 .

O grupo 4 apresentou seu estudo sobre a taxa real de juros com base no IGP-M como referência de inflação e a SELIC como base para a remuneração das aplicações financeiras. Assim como os demais grupos, os alunos apresentaram um gráfico com a evolução histórica dessas variáveis (gráfico 5).

\footnotetext{
${ }^{5}$ Alcunha dada a quem vive de renda proveniente de aplicações financeiras. Termo comumente usado por economistas para se referir à pessoas de alta renda.
}

Tangram - Revista de Educação Matemática, Dourados - MS - v.2 n. 2, pp. 67 - 86 (2019) 


\section{O juro real no contexto da educação financeira crítica}

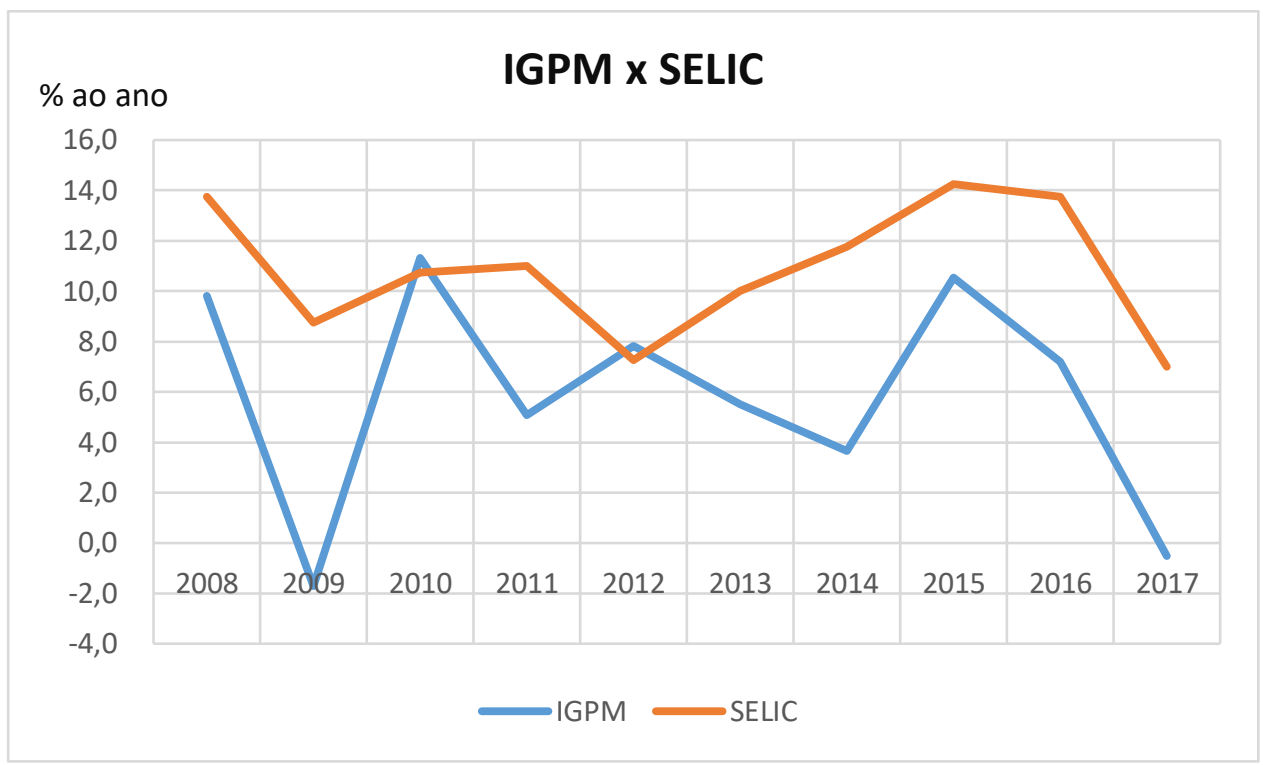

Gráfico 5: Inflação em \% ao ano (IGPM) e taxa SELIC. Fonte: dados de http://www.portalbrasil.net/igpm.htm (IGPM) e http://www.bcb.gov.br/?COPOMJUROS (SELIC), apud relatório dos estudantes

Os alunos comentaram que a taxa do Sistema Especial de Liquidação e de Custódia (SELIC) é fixada pelo Comitê de Política Monetária (COPOM) do BCB e serve como balizadora do sistema de metas de inflação. Já o Índice Geral de Preços do Mercado (IGPM) é composto pelo índice de preços por atacado (IPA), com peso de $60 \%$, índice de preços ao Consumidor (IPC), com peso de $30 \%$ e pelo Índice Nacional de Custo de Construção (INCC), com peso de 10\%, sendo calculado pela Fundação Getúlio Vargas (FGV). Esse índice é usado como indexador de contratos de aluguel, tarifas de energia elétrica, etc. No gráfico, os alunos mostraram que a SELIC superou o IGPM por pequena margem em apenas duas oportunidades (2010 e 2012). Em fevereiro de 2018, a SELIC fechou o mês em 6,75\% ao ano, o que equivale a:

$$
\begin{gathered}
1+0,0675=(1+i)^{12} \rightarrow(1,0675)^{1 / 12}=1+i \rightarrow i=1,00546-1 \rightarrow i= \\
0,00546=0,546 \%
\end{gathered}
$$

Nesse mesmo mês, a inflação medida pelo IGPM foi de 0,07\%, o que perfaz a seguinte taxa real de juro:

$$
\begin{aligned}
& 1+r=\frac{1+i}{1+j}=\frac{1+0,005458}{1+0,0007}=1,004755 \\
& r=1,004755-1=0,004755 \text { ou } 0,4755 \%^{6}
\end{aligned}
$$

\footnotetext{
${ }^{6}$ Esses cálculos de taxa equivalente e taxa real foram feitos pelos alunos na apresentação.

Tangram - Revista de Educação Matemática, Dourados - MS - v.2 n. 2, pp. 67 - 86 (2019)
} 


\section{O juro real no contexto da educação financeira crítica}

Como o IGPM serve de referência para negócios e a SELIC remunera aplicações financeiras em títulos públicos, o grupo entendeu que essa taxa real de juro seria mais aplicável aos empresários e não aos trabalhadores em geral.

O último grupo, que era o grupo 6, fez a sua apresentação e mostrou que usou como referência para o cálculo da taxa real de juro as aplicações financeiras feitas no tesouro direto, evidenciadas na figura 1.

\begin{tabular}{|c|c|c|c|c|}
\hline Título & Vencimento & $\begin{array}{c}\text { Taxa de } \\
\text { Rendimento ( } \% \\
\text { a.a.) }\end{array}$ & $\begin{array}{l}\text { Valor } \\
\text { Mínimo }\end{array}$ & $\begin{array}{c}\text { Preço } \\
\text { Unitário }\end{array}$ \\
\hline \multicolumn{5}{|l|}{ Indexados ao IPCA } \\
\hline Tesouro IPCA+ 2024 & $15 / 08 / 2024$ & 4,36 & $R \$ 46,73$ & $R \$ 2.336,99$ \\
\hline Tesouro IPCA+ 2035 & $15 / 05 / 2035$ & 5,14 & $R \$ 39,09$ & $R \$ 1.303,04$ \\
\hline Tesouro IPCA+ 2045 & $15 / 05 / 2045$ & 5,14 & $\mathrm{R} \$ 31,61$ & $R \$ 790,46$ \\
\hline Tesouro IPCA+ com Juros Semestrais 2026 & $15 / 08 / 2026$ & 4,50 & $R \$ 33,99$ & $\mathrm{R} \$ 3.399,91$ \\
\hline Tesouro IPCA+ com Juros Semestrais 2035 & $15 / 05 / 2035$ & 4,96 & $R \$ 34,95$ & $\mathrm{R} \$ 3.495,94$ \\
\hline Tesouro IPCA+ com Juros Semestrais 2050 & $15 / 08 / 2050$ & 5,09 & $R \$ 35,27$ & $\mathrm{R} \$ 3.527,25$ \\
\hline \multicolumn{5}{|l|}{ Prefixados } \\
\hline Tesouro Prefixado 2021 & $01 / 01 / 2021$ & 7,93 & $\mathrm{R} \$ 32,41$ & $\mathrm{R} \$ 810,45$ \\
\hline Tesouro Prefixado 2025 & $01 / 01 / 2025$ & 9,40 & $\mathrm{R} \$ 32,74$ & $R \$ 545,68$ \\
\hline Tesouro Prefixado com Juros Semestrais 2029 & $01 / 01 / 2029$ & 9,60 & $\mathrm{R} \$ 31,53$ & $\mathrm{R} \$ 1.051,05$ \\
\hline \multicolumn{5}{|l|}{ Indexados à Taxa Selic } \\
\hline Tesouro Selic 2023 & $01 / 03 / 2023$ & 0,01 & $R \$ 94,26$ & $R \$ 9.426,68$ \\
\hline
\end{tabular}

Figura 1: Opções de investimento em tesouro direto. Fonte: http://www.tesouro.gov.br/web/stn/tesourodireto-precos-e-taxas-dos-titulos (acesso em 28/03/2017), apud relatório dos estudantes

Mostrando a imagem da figura 1, o grupo argumentou que os títulos indexados ao IPCA apresentavam taxa real anual indicada na tabela, pois essa taxa representava o rendimento real acima da inflação medida pelo IPCA. Já os títulos prefixados teriam suas taxas reais obtidas descontando-se da taxa de rendimento a inflação futura. O último título, indexado à SELIC, teria sua taxa real calculada com base na taxa SELIC, em relação à taxa de inflação (IPCA, por exemplo), mais $0,01 \%$ ao ano.

\section{Os relatórios}

Os alunos tiveram bastante dificuldade em redigir os relatórios, mostrando pouca familiaridade com esse tipo de tarefa. Os textos apresentavam erros de língua portuguesa e Tangram - Revista de Educação Matemática, Dourados - MS - v.2 n. 2, pp. 67 - 86 (2019) 


\section{O juro real no contexto da educação financeira crítica}

falta de referência bibliográfica. Em conversa com o professor, os alunos relataram dificuldades de cooperação entre os membros dos grupos, com alunos que pouco ou nada contribuíram. Relataram ainda que acharam que o prazo para fazer o trabalho era pouco, tendo em vista que muitos alunos trabalhavam durante o dia e estudavam na faculdade à noite, tendo pouco tempo disponível para fazer atividades extras.

Não obstante, perguntados sobre a ajuda oferecida pelo professor para realizar a tarefa, os alunos disseram que isso tinha sido fundamental, pois eles estavam sem ideia de onde pesquisar os índices e estavam inseguros sobree seus cálculos.

\section{O debate}

As apresentações foram seguidas de um intenso debate, mediado pelo professor, que perguntou inicialmente aos alunos o que eles poderiam depreender dos resultados apresentados pelos grupos. O principal argumento defendido pelos alunos foi em relação aos resultados dos dois primeiros grupos, que apresentaram a taxa real para situações mais próximas à realidade da família brasileira, correspondente aos trabalhadores e às famílias que de alguma forma conseguiam guardar algum recurso na caderneta de poupança. Para essas pessoas, o risco de ter uma taxa real negativa (rendimento abaixo da inflação) era alto, o que deixou os alunos indignados.

Outro ponto levantado nas discussões foi o fato de que os gráficos apresentados pelos grupos 3 e 4, além da figura mostrada pelo grupo 5 mostravam que os rentistas e/ou empresários tinham muito mais condições de obter boas taxas reais, contrariamente ao pequeno poupador ou ao trabalhador que tem apenas o FGTS como aplicação financeira.

$\mathrm{O}$ debate prosseguiu em tom de indignação com os resultados apresentados e o professor interviu para falar sobre a taxa real de juro mostrada pelos grupos 3 a 5 , lembrando que as aplicações com base em CDI, SELIC ou mesmo o tesouro direto teriam os rendimentos tributados pelo imposto de renda (IR), que varia de 22,5\% para o curtíssimo prazo a 15\% para prazos superiores a dois anos. Além disso, o investimento no tesouro direto sofreria ainda um pequeno desconto de uma taxa administrativa, cobrada a título de custódia pela BOVESPA. Dessa forma, a taxa real líquida, comparável ao resultado apresentado pelos grupos 1 e 2, seria menor. Contudo, ponderou o professor, como o título do tesouro direto remunera sempre acima do IPCA, a sua taxa real seria sempre positiva, independente do desconto do IR.

Tangram - Revista de Educação Matemática, Dourados - MS - v.2 n. 2, pp. 67 - 86 (2019) 


\section{O juro real no contexto da educação financeira crítica}

Outro ponto levantado pelos alunos no debate foi o fato de o FGTS ser uma aplicação compulsória na qual os trabalhadores não podem intervir para escolher outro tipo de investimento. Os alunos quiseram saber o que o banco (Caixa Econômica Federal - CEF) faz com o dinheiro arrecadado pelo FGTS, pois os empréstimos concedidos por esse banco cobrariam taxas muito altas, o que se converteria em grande lucro para a instituição financeira. O professor ponderou que os recursos do FGTS são usados preferencialmente em financiamentos imobiliários e que recentemente, a CEF passou a distribuir aos trabalhadores $50 \%$ do lucro obtido com os recursos do FGTS, que seriam pagos anualmente aos trabalhadores.

\section{Análise}

A principal questão social levantada na atividade foi a dificuldade da classe trabalhadora assalariada ter acesso a boas oportunidades de investimento, ou mesmo remunerações mais justas para seus investimentos, quer seja via FGTS ou poupança, que por vezes apresentam remunerações abaixo da inflação - taxa real de juro negativa. Em contrapartida, os rentistas tem acesso a investimentos cuja remuneração está sempre acima da inflação, representando uma taxa real de juro positiva.

As questões econômicas discutidas foram principalmente relacionadas às formas de remuneração das aplicações financeiras, comportamento da inflação, o investimento compulsório do FGTS, além de mencionar a dificuldade da classe trabalhadora em ter condições de fazer investimentos financeiros.

A educação financeira se fez presente na medida em que se discutiu as possibilidades (e as impossibilidades) de investimentos e suas respectivas remunerações. Os debates relativos a esses temas e o posicionamento de indignação dos alunos frente aos fatos demonstrados evidenciaram a vertente crítica adotada na atividade. Da mesma forma, o letramento financeiro também se fez notar, tanto nos relatórios (ainda que tivessem problemas de redação) quanto nas apresentações orais, pois os alunos mostraram os cálculos efetuados e os explicaram aos colegas, agregando suas interpretações aos resultados.

Para exemplificar o tom de indignação dos alunos, reproduzimos abaixo uma de suas falas registradas no diário do professor:"O trabalhador perde dinheiro com o FGTS, sua remuneração é quase sempre menor que a inflação. Quem fica com esse dinheiro? O governo toma o dinheiro do trabalhador e ainda ganha juros fazendo empréstimos. Isso não está certo!

\section{Considerações finais}

Tangram - Revista de Educação Matemática, Dourados - MS - v.2 n. 2, pp. 67 - 86 (2019) 


\section{O juro real no contexto da educação financeira crítica}

Conforme mencionamos em nosso quadro teórico, o letramento financeiro se dá, segundo Sena (2017) quando, entre outras coisas, se desenvolve:

- A habilidade de ler, analisar e interpretar situações financeiras;

- O conhecimento de elementos básicos e necessários à matemática financeira pertinente ao contexto dos sujeitos;

- A capacidade de assumir postura crítica fundamentada;

- A capacidade de considerar variáveis e implicações de suas ações;

Todas essas habilidades, capacidades e conhecimentos foram trabalhados nessa atividade, na medida em que:

- Os alunos analisaram e interpretaram as situações financeiras propostas;

- Demonstraram conhecimentos de matemática financeira relativos ao cálculo da taxa real de juro;

- Criticaram os resultados usando argumentos fundamentados nos cálculos;

- Analisaram as variáveis envolvidas (taxas de inflação e taxas de remuneração das aplicações financeiras) de maneira coerente, constatando as relações entre elas na forma quantitativa e interpretativa.

Adicionalmente, a educação crítica se fez presente na medida em que foi exercida a competência democrática na composição da atividade, quer seja na formação dos grupos, na escolha das variáveis e nas interações professor-alunos.

A atividade de modelagem matemática se mostrou adequada à proposta, abrindo espaço para discussões sobre problemas concretos que fazem parte da realidade dos alunos e que estão ligados à formação profissional deles.

Como dissemos, houve dificuldades, mas a experiência do professor com atividades de modelagem ajudou a minimizar os problemas, na medida em que houve um atendimento prévio às demandas de dúvidas dos alunos. Com isso, acreditamos que os alunos mostraram um amadurecimento com o engajamento nas discussões das problemáticas levantadas e que isso os qualifica a terem suas dificuldades minimizadas em atividades ou situações semelhantes.

Por fim, valorizamos da conscientização social e política presente nos conhecimentos matemáticos na medida em que fortalecemos o conhecimento reflexivo da forma como Skovsmose (2004) o apresentou.

Tangram - Revista de Educação Matemática, Dourados - MS - v.2 n. 2, pp. 67 - 86 (2019) 


\section{O juro real no contexto da educação financeira crítica}

\section{Referenciais}

Barbosa, J. C. (2003). What is Mathematical Modelling? In: LAMON, S. J. et al. (Eds.). Mathematical Modelling: a way of life, pp. 227-234. Chichester/Grã-Bretanha: Ellis Horwood.

Barbosa, J. C (2006). Mathematical Modelling in classroom: a socio-critical and discursive perspective. Zentralblatt für Didaktik der Mathematik, v. 38, n. 3, pp.293-301. Disponível em: https://www.emis.de/journals/ZDM/zdm063i.html. Acesso em $27 / 03 / 2018$.

Barbosa, J. C (2007). Mathematical modelling and parallel discussions. Congress of the European Society for Research in Mathematics Education, 5th, 2007, Lárnaca, Chipre. Proceedings of the 5th CERME, p. 2101-2109. Disponível em: http://www.mathematik.uni-dortmund.de/ erme/CERME5b/. Acesso em 27/03/2018.

Campos, C. R. (2007). A educação estatística: uma investigação acerca dos aspectos relevantes à didática da estatística em cursos de graduação. Tese (doutorado em Educação Matemática), 256 fls. Rio Claro, UNESP.

Campos, C. R.; Wodewotzki, M. L. L. (2007). A educação estatística, a modelagem matemática e a educação crítica: um projeto. Revista teoria e prática da educação, v. 10, n. 3, pp. 321-331. Maringá, Paraná: UEM.

Campos, C. R.; Wodewotzki, M. L. L.; Jacobini, O. R. (2011). Educação estatística-teoria e prática em ambientes de modelagem matemática. Belo Horizonte: Autêntica.

Coutinho, C. Q. S.; Campos, C. R. (2018). Perspectivas em didática e Educação Estatística e Financeira: reflexões sobre convergências e divergências entre letramento matemático, matemacia, letramento estatístico e letramento financeiro. In: G. P. Oliveira (org.), Educação Matemática - epistemologia, didática e tecnologia, pp. 143-180. São Paulo: Livraria da Física.

D’ambrosio, U. (1991). Matemática, ensino e educação: uma proposta global. Temas $e$ Debates, ano IV, v. 3, pp. 1-15. Rio Claro, SP: SBEM.

Faro, C. (2006). Fundamentos da matemática financeira - uma introdução ao cálculo financeiro e à análise de investimento de risco. São Paulo: Saraiva.

Hazzan, S.; Pompeo, J. N. (2007). Matemática Financeira. $6^{a}$ ed. São Paulo: Saraiva.

Tangram - Revista de Educação Matemática, Dourados - MS - v.2 n. 2, pp. 67 - 86 (2019) 


\section{O juro real no contexto da educação financeira crítica}

IBGE (2018). Índice Nacional de Preços ao Consumidor - INPC. Disponível em: https://www.ibge.gov.br/estatisticas-novoportal/economicas/precos-e-custos/9258indice-nacional-de-precos-ao-consumidor.html. Acesso em 19/06/2018.

Kaiser, G.; Sriraman, B. (2006). A global survey of international perspectives on modelling in mathematics education. Zentralblatt für Didaktik der Mathematik, v. 38, n. 3, pp. 302-310. Disponível em: https://www.emis.de/journals/ZDM/zdm063i.html. Acesso em 27/03/2018.

Sena, F. D. L. (2017). Educação financeira e estatística: estudo de estruturas de letramento e pensamento. Dissertação (mestrado em Educação Matemática), 108 f. São Paulo: PUC-SP.

Skovsmose, O. (2004). Educação matemática crítica - a questão da democracia. 2a ed. Campinas: Papirus.

Enviado: 01/10/2018

Aceito: 02/12/2018

Tangram - Revista de Educação Matemática, Dourados - MS - v.2 n. 2, pp. 67 - 86 (2019) 